\title{
Evaluating English Teacher Education Programs in Indonesian Tertiary Education: A Proposed Model
}

\author{
Didin Nuruddin Hidayat \\ Department of English Education, UIN Syarif Hidayatullah Jakarta, Indonesia \\ didin.nuruddin@uinjkt.ac.id
}

\begin{abstract}
Keywords:

Evaluation,

English Teacher

Education Programs,

Peacock Evaluation

Model.

Numerous research studies on language program evaluation in many countries, for instance, Turkey (Uysal, 2012), Taiwan (Chang, 2010), Bangladesh (Rahman, 2007), Saudi Arabia (Liton, 2013) have yielded valuable ideas and insights in improving the quality of language programs. Those research studies have also expanded the plethora of discussion and have tested many 'untested' thoughts in the area of language program evaluation. Nonetheless, similar studies have not been researched much far in the Indonesian education context. The present study aims to describe the importance of English teacher education program evaluation. Also, the study aims to explore a suitable evaluation model in evaluating English teacher education programs, particularly in the Indonesian tertiary education context. The findings of the study found Peacock's (2009) model as a potential evaluation model to apply in evaluating English teacher education programs. These are based on at least three following grounds: suitable to the needs and environment of English teacher education in Indonesia, reliable and informative evaluation, and thorough involvement of the inner circle stakeholders. The study concludes that if an evaluation is conducted properly, then it has the potential to improve the quality of English language teachers training programs.
\end{abstract}

Article History:

Received: 24-06-2018

Revised : 18-08-2018

Accepted: 28-08-2018

Online : 30-08-2018

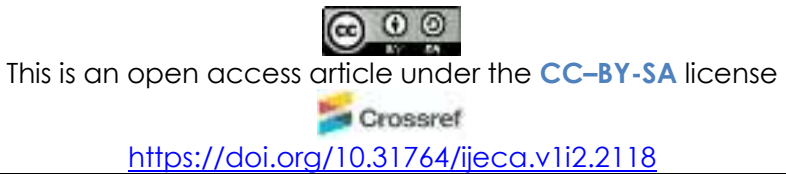

\section{A. INTRODUCTION}

Evaluation is an integral part of a language program that can yield numerous benefits. Evaluation can be utilized to determine the success or failure of the teaching and learning process as well as promote improvement for the overall program. Evaluation involves a systematic and continuous process to efficiently determine the effectiveness of teaching and learning activities and the achievement of the planned instructional objectives (Gronlund, 1981). Due to its potential benefits, scholars have carried out rigorous research studies with regards to the evaluation of teaching and learning in English as a Second/Foreign Language (ES/FL) settings in different countries, for instance, Turkey (Uysal, 2012), Taiwan (Chang, 2010), Bangladesh (Rahman, 2007), and Saudi Arabia (Liton, 2013). However, there has been limited research on the evaluation of English programs in Indonesia (for samples of research studies, see Rohmah, 2010; Wati, 2011). In light of the potential benefits of the research studies of 
English program evaluation and widespread regions in Indonesia, rigorous studies are deemed essential to conduct.

Exiguous research studies on English teacher training evaluation in the Indonesian context, to the best of the researcher's knowledge, can be found in the literature. Of the few is an evaluation study by Wati (2011), where she investigated the effectiveness of an English teacher training program as well as identified the future needs of a similar program. The participants of the study comprised of 55 elementary school English teachers responding to the questionnaires provided. The responses gained from the participants are that the training was considered as effective in improving their motivation and confidence. However, the participants highlighted that the content of the teacher training would be more beneficial if materials upgrading their language skills were also stressed. They believed that they needed to improve their English skills along with the need to improve their teaching skills. The results also suggested that a long-term training program covering both teaching skills and language proficiency should be provided in the future teacher training program to achieve the maximum result. As opposed to the research study conducted by Wati (2011), which only employed a single data source through questionnaires, an evaluative study by Rohmah (2010) employed multiple data sources derived from questionnaires, document reviews, and focus group discussions. She evaluated an inservice English teacher training program called English Language Training for Islamic Schools (ELTIS) managed under a program of Learning Assistance Programs for Islamic Schools. The study reported that the teachers' competence in English teaching skills, general teaching skills, language proficiency motivation and confidence improved. The study also revealed that though supports from schools were regarded as adequate, on the contrary, supports from parents were quite sceptical. Other interesting findings are that even though the materials taught at the program were not entirely suitable to the context of Islamic schools, the trainees believed that the materials met the Islamic schools' needs and used in their classroom practices.

The present study attempts to analyze the potential use of an evaluation model that fits to apply in Indonesian English teacher training programs. The focal point of this paper is to describe why evaluation is critical and why the chosen evaluation model can serve as a potential means of evaluating the pre-service English teaching programs, more specifically at tertiary education in Indonesia. Evaluation at the tertiary level is necessary in that it serves as a guideline for evaluation for the lower education level. The study should be useful to promote a potential model of evaluation of English language teacher preparation programs. This, in turn, will lead to improving the quality of English language teacher preparation programs in Indonesia.

\section{B. METHODS}

The present study employed a literature web-based survey research. There are two kinds of methods of web-based surveys: non-probability and probability (Couper, 2000). The present study adopted the latter method, probability, by finding the sample from the populations. The operational technique was conducted through a quick Google search on the internet. After conducting a quick search through the internet, it was found some promising evaluation models that have been used by language researchers and educators in evaluating the effectiveness of English language and education programs.

The search for evaluation models from the internet that fit for English language and education programs generated several results. Among others are the Contex-Input-Process- 
Product evaluation model developed by Stufflebeam (1983). A further widely-used evaluation model for education programs found on the internet was the four-level evaluation model developed by Kirkpatrick and Kirkpatrick (1996), which consisted of four levels: reaction, learning, behavior, and results. Another promising evaluation model found from internet search and was applied widely by language researchers and educators was an evaluation model pioneered by Peacock (2009). Concerning a more updated evaluation model and also a closer look at the evaluation program focusing on improving the quality of English training programs, the researcher chose Peacock (2009) as one of the promising evaluation models that may cater best to the needs of English training programs in the Indonesian context.

\section{RESULT AND DISCUSSION}

Peacock (2009) developed his teacher-training evaluation model drawing from relevant literature regarding the compelling content and procedures of the EFL teacher-training education program. The initial essential criterion that a teacher training should possess is a clearly stated philosophy and whether the content of the program reflects its philosophy. He also argues that the program should include a balance between received knowledge versus experiential one as well as a balance among linguistic (L2 proficiency, pedagogic (teaching skills, knowledge of language and second language acquisition), and managerial competence. Peacock also highlights that the program should adequately train in its teacher trainees the skill in employing different teaching approaches for different situations and the ability to use and to adapt FLT materials. Another essential element that should include in a teacher-training program, according to Peacock, is reflection. He elaborates further that the reflection consists of a reflection on the experiences and values the teacher trainees possess when enrolling in the program. Besides, the reflection and self-evaluation skills as a teacher, as well as future reflective practice, are inseparable from the teacher training program. An effective teacher training program should promote a long-term and developmental character of learning to teach. Likewise, the proposed Peacock model emphasizes coherence linkage among courses, which avoids overlaps, balance between teacher-centered and student-centered learning, and up-todate program. The teacher training program should also prepare the trainees to adapt to their future sociocultural work context. The final criterion that should include is an evaluation of whether the program meets and relevant to the students' needs and also prepare them for classroom teaching. The abovementioned criteria were then further employed to produce a set of questions for evaluating the teacher trainee program.

It is widely believed that there is no evaluation model claimed as the best evaluation model suiting different contexts; the decision to choose an evaluation model relies on the specific situation which will be investigated. The rationale for choosing Peacock's evaluation model is multiple. Peacock's evaluation model meets the specific context of the proposed research study, which is the English teacher-training program. Other evaluation models, e.g., Kirkpatrick and Kirkpatrick's (1996) Four-Level Evaluation, Stufflebeam's (1983) Context Input Process Product (CIPP), Davis' (1981) Process Model are not explicitly designed for English teacher training programs. A further reason is that clear, explicit criteria have been set up in Peacock's evaluation model. This is considered essential in order to reach a reliable, fair, and informative evaluation; besides explicit, criteria should also be identified (Rea-Dickins \& Germaine, 1993). In short, conducting evaluation has to be systematic and follow certain guiding principles employing criteria that have been carefully designed. 
Further, Peacock's evaluation model complies with the social interaction model. Rea-Dickins \& Germaine (1993) classify two models of introducing the innovation of the evaluation: the research, development \& diffusion model, and the social interaction model. The former tends to exclude the involvement of the direct parties, e.g., teachers and students, and thus innovation, as a result of the evaluation, has a more substantial potential to be rejected. On the contrary, the social interaction model includes collaboration and participation from the inner circle directly involved in the program. English education programs should ideally invite active contributions from teachers, students, alumni, and program coordinators in the evaluation process. Thus, Peacock's evaluation model complies with the approach of the abovementioned condition. Papineau and Kiely (1996) argued that if the stakeholders are engrossed in the evaluation process, it will lead to numerous benefits; one of them is it will enhance the evaluation result as it represents the values and concerns of the multiple groups involved in decision-making. Another salient benefit is that it promotes a sense of belonging, establishes trust, and increases interaction as well as collaboration between community members.

\section{CONCLUSION AND SUGGESTIONS}

This paper has argued the importance of evaluating English teacher education programs and elaborated on how Peacock's (2009) evaluation model can be a potential tool to evaluate such programs. By comprehensively evaluating the EFL teacher-training program, the strengths and weaknesses of the program would be uncovered and become apparent. Thus, specific follow up actions and strategies for improving the quality of the program can be planned based on the findings of the proposed evaluation study. The need for evaluation and an established model of teacher training evaluation is vital, considering research studies findings on revealing the benefits of evaluation. The present study may also provide a significant contribution to a more effective teacher training program evaluation, which will lead to producing more qualified graduates whom most of them will teach at primary, secondary and even higher education levels.

\section{REFERENCES}

Chang, Y. (2010). English-medium instruction for subject courses in tertiary education: Reactions from Taiwanese undergraduate students. Taiwan International ESP Journal, 2(1), 55-84.

Couper, M. P. (2000). Web-based surveys: A Review of Issues and Approaches. Public Opinion Quarterly, 64, 464-494.

Davis, E. (1981). Teachers as curriculum evaluators. Allen and Unwin.

Gronlund, E. (1981). Measurement and evaluation in teaching. Macmillan.

Kirkpatrick, D. L., \& Kirkpatrick, J. D. (1996). Evaluating training programs. BerrettKoehler Publishers.

Liton, H. A. (2013). An assessment of the efficacy of Engineering ESP teachers' training program in promoting better performance at ESP classroom. English for Specific Purposes World, 37(13), 1-17.

Papineau, D., \& Kiely, M. (1996). Participatory evaluation in a community organization: Fostering stakeholder empowerment and utilization. Evaluation and Program Planning, 19(1), 79-93. 
Peacock, M. (2009). The evaluation of foreign-language-teacher education programmes. Language Teaching Research, 13(3), 259-278.

Rahman, M. H. (2007). An evaluation of the teaching of reading skills of English in Bangladesh. University of Rajshahi Dhaka.

Rea-Dickins, P., \& Germaine, K. P. (1993). The price of everything and the value of nothing: Trends in language programme evaluation. In P. Rea-Dickins \& K. P. Germaine (Eds.), Managing evaluation and innovation in language teaching: building bridges (pp. 3-19). Longman.

Rohmah, Z. (2010). English language training for Islamic schools (ELTIS): Trainees' outlook. Jurnal Bahasa Dan Seni, 38(1), 117-129.

Stufflebeam, D. L. (1983). The CIPP model for program evaluation. Kluwer-Nijhoff.

Uysal, H. H. (2012). Evaluation of an in-service training program for primary-school language teachers in Turkey. Australian Journal of Teacher Education, 37(7), 14-29.

Wati, H. (2011). The effectiveness of Indonesian English teachers training programs in improving confidence and motivation. International Journal of Instruction, 4(1), 79-104. 